\title{
Cantos e memória nas narrativas históricas dos Suruí de Rondônia (Amazônia Brasileira)
}

\author{
Songs and memory in historical narratives of the Surui of \\ Rondônia (Brazilian Amazonia) \\ Cédric Yvinec
}

RMA

Dossier

CNRS, Mondes Américains, Paris, França. Email: cedric.yvinec@ehess.fr

\begin{abstract}
Resumo
Este artigo estuda um gênero de cantos rituais de um povo indígena da Amazônia brasileira, os Suruí de Rondônia, para analisar o seu papel na construção da memória histórica. O artigo pretende demonstrar que, ao contrário das teorias que afirmam que os grupos das Terras Baixas constituiriam "sociedades frias" que negariam sua historicidade e tentariam esquecer seu passado, estes povos têm desenvolvido instrumentos próprios para selecionar e transmitir lembranças de alguns tipos de eventos. O artigo apresenta as formas retóricas e estéticas destes cantos, os seus usos pragmáticos e as teorias metalinguísticas dos Suruí sobre esta arte verbal para explicar por que este gênero discursivo representa a forma mais perfeita de fala no contexto da composição inicial de um canto. Por fim, o artigo examina os usos conversacionais das citações de cantos antigos em relatos históricos para mostrar que as estruturas narrativas, em particular as conexões entre eventos evocados, estão determinadas pelas propriedades retóricas e estéticas dos cantos citados.
\end{abstract}

Palavras-chave: Amazônia indígena; Suruí de Rondônia (índios); canto ritual; historicidade; narrativa.

\begin{abstract}
This article studies a specific genre of ritual songs among an indigenous people of Brazilian Amazonia, the Surui of Rondônia. It analyses the influence of these songs on the construction of historical memory. Against theories that reduce the Lowland Indians to "cold societies" that would supposedly deny their own historicity and strive to forget their past, the article shows that these peoples have developed their own tools to select and pass down memories of some kinds of events. The rhetorical and aesthetical forms of these songs, their pragmatic uses, and the Surui metalinguistic theories are analysed, so as to explain why this discursive genre can appear as the most perfect kind of speech, in the context of the initial composition of a song. Finally, the article examines the conversational uses of quotations of old songs in historical accounts and shows that the narrative structure, particularly the connections between the evoked events, are determined by the rhetorical and aesthetical properties of the quoted songs.
\end{abstract}

Keywords: indigenous Amazonia; Suruí of Rondônia (Indians); ritual song; historicity; narrative.

As sociedades indígenas das Terras Baixas da América do Sul têm a reputação de desconsiderar o seu próprio passado. A memória histórica nestas sociedades seria pouco desenvolvida, as suas narrativas sobre o passado se confundiriam com a mitologia (Overing 1977). Com efeito, é difícil afirmar que se acharia nas tradições destas sociedades um uso do passado semelhante ao das sociedades ocidentais: aqui não se encontram as narrativas complexas, múltiplas e detalhadas, orais ou escritas, que pretendam legitimar o poder político pela narração dos eventos testemunhados, datáveis, localizados e atribuídos a agentes humanos, mais ou menos semelhantes aos humanos do presente (Fausto e Heckenberger 2007). Contudo, o fato de que não existe tal uso do passado não implica não haver uso algum do passado nas sociedades indígenas das Terras Baixas. Por não achar o passado evocado numa forma retórica igual àquela usada na tradição ocidental, não se pode concluir que esse passado não apareça em nenhuma outra forma retórica nas tradições dessas várias sociedades. Porém, as formas retóricas da evocação do passado têm uma influência sobre os eventos que são escolhidos para serem evocados; esta influência deve ser descrita.

Este artigo, baseado na etnografia linguística de um povo da Amazônia brasileira, os Suruí de Rondônia, pretende analisar o papel de uma forma retórica culturalmente específica - mas frequente entre os povos das Terras Baixas - na formação e na transmissão da memória histórica: cantos e citações destes cantos em discursos narrativos. Com efeito, os cantos são a forma mais valorizada da fala entre os Suruí. Ainda que as ocasiões 
para compor novos cantos sejam raras hoje, os cantos compostos servem nas conversações cotidianas para evocar o passado e situar eventos no tempo. Ora, tanto a própria forma linguística, retórica e poética desta arte verbal como as teorias reflexivas sobre tais práticas orientam e estruturam a memória histórica deste povo.

\section{O contexto etnográfico}

Os Suruí de Rondônia - autodenominados Paiterey, "Nós mesmos" - são uma população indígena de mais ou menos 1.200 indivíduos hoje. ${ }^{1}$ Eles moram na Terra Indígena Sete de Setembro, que fica na divisa entre os estados de Rondônia e Mato Grosso. Eles falam uma língua da família tupi-mondé, uma pequena família do tronco tupi. Até que fossem contatados pela Funai em 1969, eles mantinham relações belicosas com as populações vizinhas. Naquele tempo, eles somavam provavelmente 500 indivíduos (Chiappino 1975).

Moravam numa única aldeia, ou em duas aldeias apenas - vivendo da caça e da horticultura, precisavam mudar sua(s) aldeia(s) a cada dois ou três anos para abrir novas roças. Este padrão residencial indica que a população suruí estava bastante concentrada em comparação com vários grupos da Amazônia, muitas de suas atividades sendo públicas - pelo menos as que se faziam na aldeia. As distinções em termos de reconhecimento, prestígio, poder e riqueza hortícola, artesanal e matrimonial entre os homens eram muito fortes, bem distante da imagem igualitária dos povos amazônicos. Alguns indivíduos tinham mais de cinco esposas, conseguiam produzir excedentes alimentares para gastar em consumo conspícuo, trocavam bens prestigiosos quando outros estavam solteiros, faltavam ornamentos, passavam fome. Estas diferenças eram parcialmente herdadas em linha patrilinear e as riquezas, em especial as mulheres, eram largamente monopolizadas pelos homens maduros - a regra de casamento avuncular (do tio materno com a sua sobrinha) exigia paciência por parte dos jovens homens. Porém, estes tinham a oportunidade de conquistar tais bens através da participação nas expedições de guerra (contra outros índios) ou do roubo de ferramentas metálicas (nos barracos de seringueiros). O homicídio ou, pelo menos, a tentativa de homicídio - e o roubo de facões permitiam ganhar esposas, que eram produtoras de ornamentos, e ampliar os roçados para produzir mais milho, carás, batatas e, finalmente, mais chicha.

De fato, essas eram as atividades mais valorizadas, pelo menos por homens: a guerra e a participação nas festas de chicha. Ora, tais eventos eram - e são - os que mais legitimam a composição de um novo canto merewá. Vários outros acontecimentos podem também motivar a

\footnotetext{
${ }^{1}$ Os dados etnográficos foram coletados em 2005-2007, 2013 e 2015. Para informações etnográficas mais detalhadas, ver Mindlin (1985) e Yvinec (2011a). Os Suruí de Rondônia não devem ser confundidos com o grupo homônimo, falante de uma língua tupi-guarani, que vive no Pará e não tem nenhuma relação com eles.
}

invenção de uma canção deste gênero: relação adúltera, pesca com timbó, coleta de larvas, construção de uma nova maloca, etc. Porém, estas atividades podem ser analisadas como imagens ou ecos das primeiras em vários aspectos, e os cantos compostos em tais ocasiões serão sempre menos valorizados do que os que celebram uma guerra ou uma festa de chicha.

\section{Os cantos merewá no sistema dos gêneros discursivos suruí}

A língua suruí não tem uma palavra específica para se referir à fala cantada como tal. Com efeito, os Suruí distinguem dois tipos de cantos: os cantos xamânicos - designados em português como "música do pajé" ou "música dos espíritos" - e os outros, descritos como "música de pessoas". Os cantos xamânicos são designados por uma palavra específica: o verbo pereiga, literalmente "tirar (iga) de maneira intensa e repetitiva (pere)". O objeto direto deste verbo é sempre o nome de um espírito (mẽbetih-pereiga, "tira de maneira repetitiva o espírito Queixada"), um nome de uma espécie de espírito (ğoaney-pereiga, "tirar de maneira repetitiva os espíritos aquáticos"), ou um pronome indefinito para se referir ao conjunto dos espíritos e, assim, ao canto xamânico de maneira genérica (so-pereiga, "tirar algo de maneira repetitiva", quer dizer, "cantar uma canção xamânica").

Cada canto xamânico, designado pelo nome de um espírito, tem um conteúdo fixo, que é a própria fala do espírito em questão. A enunciação do canto assinala a presença - invisível, exceto para os xamãs - do espírito e sua atividade a serviço do cantor, que se manifesta por efeitos físicos, principalmente a cura de doenças. A linguagem que estes cantos usam é bastante diferente da linguagem cotidiana. Poucas pessoas a entendem, e ainda menos a falam: xamãs confirmados ou homens que já tiveram uma experiência de revelação xamânica. Por isso, não é qualquer um que pode enunciar cantos xamânicos; apenas pessoas escolhidas pelos espíritos podem fazê-lo. Essas pessoas são chamadas wãwã, uma palavra impossível de decompor etimologicamente (opacidade semântica), que pode ser traduzida por "xamã". Eles precisam ter recebido uma revelação onírica dos espíritos para enunciarem sua fala sem perigo de enraivecê-los e serem castigados por eles. Então, para usar a terminologia de Goffman (1979), o xamã cantante é apenas o "animador" do discurso; o "autor" e o "responsável" é o espírito.

Isto distingue os cantos merewá dos cantos xamânicos: o enunciador humano dos primeiros deve ser o seu "autor", no sentido de Goffman. Com efeito, os cantos merewá, categoria que une todos os discursos cantados que não são cantos xamânicos, só podem ser compostos para alguns atos específicos - homicídio, roubo de facões, tomada de chicha, adultério, etc. - pelo autor do ato. O indivíduo que compõe o canto o cantará primeiro 
e será lembrado como seu autor - habitualmente é um homem, porém acontece que algumas (poucas) mulheres compõem e cantam cantos merewá. Não conheço nenhuma palavra da língua suruí que traduza o conceito de "autor", mas em reposta à pergunta Nan ana merewá yã?, "Quem cantou assim?", após ouvir um canto merewá, um Suruí sempre dará a identidade do compositor e cantor inicial - o "autor", no sentido de Goffman - mesmo se nessa ocasião o canto for enunciado por um outro indivíduo - o "animador", ainda conforme Goffman. Portanto, os Suruí traduzem a palavra merewá como "música de pessoa". Regra geral, estes cantos são cantados - e, supostamente, também compostos depois de se completarem os atos que os ocasionaram: quando o inimigo já morreu, quando os facões já foram trazidos para a aldeia, quando o tomador de chicha já está bêbado, quando a mulher já foi seduzida. O canto simplesmente destaca que este ato aconteceu, usando a linguagem comum, compreendida por todos os Suruí, adultos ou adolescentes. Por isso, estes cantos não têm efeitos diretos ou, pelo menos, os seus efeitos não são tão diretos como os dos cantos xamânicos. Assim, eles não têm nenhum poder mágico, ao contrário dos cantos xamânicos.

\section{O objeto e o responsável pela música}

Se o "autor" goffmaniano de um canto merewá pode ser definido sem dificuldade, a identificação do "responsável" e do "animador" é mais complexa. A palavra merewá significa "falar (-ewá) de maneira repetitiva e intensa (-pere-)". Este é apenas um termo genérico que se refere a todo tipo de fala cantada - fora dos cantos xamânicos - sobre qualquer sujeito. ${ }^{2} \mathrm{Na}$ conversa cotidiana, o uso desta palavra é raro, pois, quando os Suruí se referem a um canto específico, usam apenas o verbo que constitui o radical de merewá: ewá, "falar" ou "dizer". Quando este verbo é usado no intransitivo ou de forma reflexiva, ele significa apenas o ato de falar: awewá (a-we-ewá, 3refleXIVo-RefleXIVo-falar), "ele/ela está falando" ou "eles estão conversando".

Porém, quando este verbo é utilizado como transitivo, isto quase sempre implica que a fala é cantada. Se não fosse, se usaria apenas uma locução feita de um pronome, da partícula causativa ma, que significa mais ou menos "fazer", e de um objeto indireto: ewema X-ka (ewe-ma $\mathrm{X}$-ka, ENDOFORICO-CAUSATIVO X-dATIVo), "fazer [saber] disso a X", "informar X disso". Agora, quando é usado como intransitivo, o verbo ewá não tem nenhum objeto indireto; o objeto direto pode ser de vários tipos, do ponto de vista semântico. Ele pode se referir a uma atividade genérica:

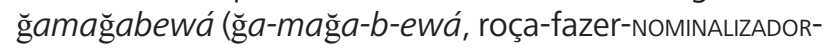

\footnotetext{
${ }^{2}$ Não existe no vernáculo uma locução semanticamente equivalente à expressão "música de pessoas" que os Suruí usam para explicar aos antropólogos a diferença pragmática entre os cantos xamânicos e os não xamânicos. Para os Suruí, parece evidente que, com exceção dos cantos xamânicos, todos os cantos são compostos por aqueles que os enunciam ou os enunciaram primeiro.
}

falar), "dizer a roçadura", "enunciar um canto sobre a roçadura"; paloakabewá (palo-aka-b-ewá, INDEFINITO. HUMANO-matar-NOMINALIZADOR-falar), "dizer o homicídio", "enunciar um canto sobre uma guerra"; ihatirabewá (ih-atir-a-b-ewá, água-doído-comer-NOMINALIZADOR-falar), "dizer a tomada de chicha", "enunciar um canto de festa". O objeto direto de ewá pode também ser um evento específico: X-siabewá (X-si-a-b-ewá, X-águacomer-NOMINALIZADOR-falar), "dizer a tomada da chicha [chamada] X", "enunciar um canto naquela festa em que a chicha foi apelidada X"; Y-akabewá (Y-aka-b-ewá, Y-matar-nominalizAdor-falar), "dizer o assassinato de $Y$ ", "enunciar um canto celebrando o assassinato do [inimigo apelido] Y"; iwewá (iwe-ewá EXOPHORIco-falar), "dizer isso", "enunciar um canto sobre isso".

Enfim, o objeto direto do verbo ewá pode ser uma pessoa: X-ewá (X-falar), "dizer o indivíduo X", "enunciar um canto sobre a atuação de $X$ como produtor de chicha ou como amante". A diferença entre "informar" (-ma, em fala falada) e "dizer" (ewá, em fala cantada) parece ser que "dizer" implica uma relação forte entre o ato locutório e o objeto cantado. Um evento é realmente "dito", completamente descrito, plenamente enunciado apenas quando esta evocação é feita em fala cantada. O desaparecimento do objeto indireto naquelas frases indica que o objeto cantado é agora reconhecido não por um destinatário específico, mas sim por qualquer um.

Posto que é possível substituir uma referência ao evento particular tanto por uma referência à identidade do indivíduo (outro que o autor do canto) implicado neste evento como por uma referência ao tipo de atividade a que este evento pertence, pode-se concluir que eles são equivalentes a partir de algum ponto de vista. O evento evocado pelo canto é importante porque cabe numa categoria definida e, ao mesmo tempo, supõe uma interação do autor do canto com um outro indivíduo. Ora, nas categorias de eventos cantáveis, este outro indivíduo implicado está sempre em uma relação tensa, conflituosa ou agonística com o cantor. Nos cantos de guerra, este antagonismo é óbvio: o indivíduo cantado é sempre a vítima do cantor, aquele que se espera ou que já foi morto.

Os cantos de adultério resultam de queixas ou desafios da amante e provocam conflitos com os maridos enganados, até mesmo pelo fato de serem cantados. Nas festas de chicha, ocasiões mais frequentes para compor cantos, há uma dupla rivalidade: uma, aberta, entre produtores e consumidores da chicha; e outra, menos comentada, entre os vários tomadores, que compõem cantos ao mesmo tempo, para destacar o mais escutado e o mais apreciado. Em várias situações em que se compunham cantos, ciúmes e conflitos eram comuns: havia bens raros ou prestigiados em jogo, quando se celebrava o roubo de ferramentas metálicas ou uma pesca com timbó. 0 antagonismo patente ou latente entre o autor do canto 
e seu objeto parece necessário para que a expressão cantada seja possível ou relevante - se não há nenhum desacordo numa atividade, não vale "dizê-la" (-ewá), basta "informar" (-ma) sobre este assunto de pouco importância.

\section{A forma musical e retórica dos cantos merewá}

Os cantos merewá são sempre cantados a cappella; o único acompanhamento é o ritmo do chocalho de pé se o cantor dançar (principalmente nos cantos de festa). ${ }^{3}$ A duração de um mesmo canto pode variar, em função das condições de enunciação, de 10 segundos até 20 minutos. Nas condições da enunciação original, no momento da festa, por exemplo, um canto dura entre 10 e 20 minutos. Quando é cantado de novo depois, por exemplo, a pedido do antropólogo, não dura mais que 5 ou 7 minutos. Quando é citado numa conversação, não dura mais que 30 segundos e pode se resumir a algumas palavras rapidamente pronunciadas quase sem cantá-las.

Todos os cantos apresentam uma estrutura paralelística. Em cada canto há um leitmotiv - uma expressão que se encontra em todas as frases da música. Habitualmente este leitmotiv aparece nas primeiras e nas últimas palavras de cada frase. Na escala de um canto, o leitmotiv é uma constante. Contudo, na escala de um gênero lírico - isto é, um tipo de canto definido pela situação ou a atividade que motivou a sua composição - cada leitmotiv aparece como uma variável. Com efeito, as palavras que variam ao longo de um canto reaparecem mais ou menos em quase todos os cantos que pertencem ao mesmo gênero.

Isto pode ser visto nos exemplos (1) e (2), comparando dois cantos de um gênero pouco importante, labaãbewá, "dizer a construção de maloca", mas bem claro.

(1) Owener axiter, ikõrey xi i

Owener axiter, ikõrey xa mammóyheperẽkabi ter asabakãresahraã kaled $\boldsymbol{i}$, tasa ye $\boldsymbol{i}$

Owener axiter, ğamebey xi $i$

Owener axiter, ğamebey xa mammóyhekãyataga ye $i$, tasa ye $i$

"Eu sou aquele que fala isso de verdade", os gaviões deveriam falar assim

"Eu sou aquele que fala isso de verdade", os gaviões deveriam falar assim quando trazem o esqueleto da sua casa para a forquilha da grande castanheira, deveriam falar assim

"Eu sou aquele que fala isso de verdade", os marimbondos deveriam falar assim

"Eu sou aquele que fala isso de verdade", os marimbondos deveriam falar quando furam a grande castanheira seca, deveriam falar assim

(2) Enekida bo meyya meyxabamamoga te ikaya-

\footnotetext{
${ }^{3}$ Em apenas uma espécie de festa, os cantos são precedidos pelo toque de flautas.
}

reh, te oliyã, ikõreyka oliyã

Enekida bo meyya mey-xabamamoga mammóyheperẽabikoy yenareh, te oliyã, ikõreyka oliyã

Enekida bo meyya enareh, te oliyã, ğamebey-ka oliyã

"Agora juntem tudo o que precisam para [construir] sua casa", pessoas dizem que estou falando isso para os gaviões

"Agora juntem tudo o que precisem para [construir] sua casa na forquilha da grande castanheira", pessoas dizem que estou falando isso para os gaviões

"Agora façam isso", pessoas dizem que estou falando isso para os marimbondos

Constata-se que as mesmas palavras, ikõrey, "os gaviões", ğamebey, "os maribondos pretos", mammóhyeperẽ, "a forquilha da castanheira grande" (sublinhadas no texto suruí) encontram-se nos dois cantos. Estas são metáforas recorrentes nos cantos que celebram a construção de uma maloca. Ao contrário, as expressões Owener axiter ... sa $i$, "Eu sou aquele que fala isso de verdade ... deve falar assim" e Enekida bo meyya ... reh ... ka oliyã, "Agora vocês devem... pessoas dizem que estou falando isso para..." (em negrito no texto suruí) são elementos que pretendem distinguir cada um destes cantos de todos os outros cantos do mesmo gênero.

Do ponto de vista sintático, estes dois elementos retóricos - leitmotiv individualizante e metáforas que se acrescentam à estética específica de um gênero lírico estão estreitamente ligados. O leitmotiv constitui amiúde um discurso citado (em negrito), quando os elementos variáveis ao longo do canto aparecem como elementos centrais do discurso citado (sublinhado):

"Owener axiter", ikôrey xi $i$

"Eu sou aquele que fala isso de verdade", os gaviões deveriam falar assim

Aqui, neste discurso citado, os elementos variáveis ao longo do canto constituem mais especificamente o agente de uma partícula verbal (-sa / xa / xi) que faz parte do leitmotiv. Em outros casos, eles podem constituir o objeto indireto de um grupo verbal, parte do leitmotiv em que o agente está incluído:

\section{Enekida bo meyya enareh, te oliyãa ğamebeyka oliyã}

"Agora façam isso", pessoas dizem que estou falando isso para os marimbondos

Nunca o leitmotiv e as metáforas aparecem como frases independentes, como se constituíssem um refrão ou uma estrofe.

Do ponto de vista semântico, o leitmotiv não aparece sujeito a nenhuma regra. Ao contrário, os elementos 
variáveis ao longo de um canto e fixos na escala do gênero lírico sempre são metáforas que se referem aos parceiros da atividade que motiva a composição de música deste gênero, ou a alguns aspectos centrais desta atividade. Nos exemplos anteriores, estas metáforas dizem respeito à escolha do melhor lugar para a nova aldeia ("a forquilha da castanheira"), à perícia arquitetural ("os gaviões, os marimbondos", enquanto bichos que constroem ninhos conspícuos) e à sociabilidade para reunir parentes ("os marimbondos", como inseto social).

\section{O gênero musical como "linguagem"}

Estes elementos lexicais variáveis ao longo de uma música formam um conjunto. Alguns deles reaparecem quase idênticos em todas as músicas do mesmo gênero; nem todos estão sempre presentes num determinado canto. Dois cantos podem não apresentar um elemento absolutamente igual. Assim mesmo, todos os cantos de um gênero apresentam uma "semelhança de família", o que permite reconhecer que um determinado canto pertence a este gênero. ${ }^{4} \mathrm{O}$ conjunto destes elementos lexicais constitui um padrão metafórico que cada cantor deve seguir quando compõe uma nova obra lírica. $\mathrm{Na}$ tabela 1 podem ser vistas as imagens mais comuns dos padrões metafóricos próprios a alguns gêneros de cantos. Constata-se que muitas destas metáforas baseiam-se em

\footnotetext{
4 Meu caso pessoal permite medir esta semelhança: com minha experiência de tradução de algumas centenas de cantos - isto é, bem menos do que um adolescente suruí pode ter ouvido - frequentemente já sou capaz de identificar um canto ao ouvi-lo.
}

inversões clássicas nas estéticas das Terras Baixas (guerra / agricultura, humano / animal, etc.)

Além deste padrão metafórico, cada gênero lírico se caracteriza por uma sonoridade. Ela é bastante difícil de analisar em razão da pobreza do vocabulário reflexivo neste assunto e da falta de saliência destes contrastes musicais para um ouvido não suruí - a sonoridade própria de cada gênero lírico parece definir-se mais pelo volume do que pela altura ou pela melodia. ${ }^{5}$ Do ponto de vista dos Suruí é o conjunto do padrão metafórico e da sonoridade - que eles chamam de "som", em português - que define "a linguagem" própria para "dizer" uma atividade que motiva a composição de um canto. Em suruí, há uma palavra única para se referir à sonoridade musical e ao estilo metafórico que todos os cantos de um gênero devem seguir: koe. Esta é uma palavra muito comum que pode se relacionar com quase todos os sons intencionais de origem interna, quer sejam propriamente vocais ou não. Usa-se para se referir às linguagens de povos humanos: pağoe (pa-koe, 1 pl.INCLusivo-linguagem), "nossa língua", isto é, o suruí; yarakoe (yara-koe, brancolinguagem), "a língua do branco", isto é, o português; lahdğoesor (lahd-koe-sor, inimigo-linguagem-feio), "a língua feia do inimigo", isto é, a língua dos Zoró (um grupo tupi-mondé vizinho).

Usa-se também para fazer menção às linguagens de coletivos não humanos: soeykoe (so-ey-koe, INDEFINITO.

\footnotetext{
${ }^{5}$ Apesar de eu poder identificar o gênero ao qual um canto pertence pelas suas palavras, sou quase incapaz de identificá-lo pela música.
}

Tabela 1. Padrões metafóricos de alguns gêneros líricos

Table 1. Metaphorical patterns of a few lyrical genres

\begin{tabular}{|c|c|c|c|}
\hline Nome do gênero lírico & & Contexto & Imagens \\
\hline ariya-ewá & "dizer a preguiça" & festa & $\begin{array}{l}\text { espírito } \\
\text { monstruoso } \\
\text { velhinha }\end{array}$ \\
\hline lahd-niğ-ewá & "dizer o inimigo pintado" & festa & $\begin{array}{l}\text { guerra } \\
\text { facão }\end{array}$ \\
\hline ğer-mabi-ewá & "dizer o retorno da caça" & festa & fome \\
\hline ğa-mağa-be-ewá & "dizer a roçada" & festa & $\begin{array}{c}\text { guerra } \\
\text { caça } \\
\text { pica-pau }\end{array}$ \\
\hline $\begin{array}{l}\text { mapi-ma-ih-ewá } \\
\text { palo-aka-be-ewá }\end{array}$ & $\begin{array}{l}\text { "dizer a festa mapi-ma-ih" } \\
\text { "dizer o homicídio" }\end{array}$ & $\begin{array}{l}\text { festa } \\
\text { guerra }\end{array}$ & $\begin{array}{c}\text { gavião } \\
\text { urubu, abelhas, } \\
\text { cotia } \\
\text { queixada } \\
\text { roçada }\end{array}$ \\
\hline $\begin{array}{l}\text { palo-aka-be-kanẽ-e- } \\
\text { ewá }\end{array}$ & $\begin{array}{l}\text { "dizer a vontade de } \\
\text { homicídio" }\end{array}$ & guerra & $\begin{array}{c}\text { caça } \\
\text { roçada }\end{array}$ \\
\hline $\begin{array}{l}\text { yara-txãbekod-aã-e- } \\
\text { ewá }\end{array}$ & $\begin{array}{l}\text { "dizer o roubo de facões do } \\
\text { branco" }\end{array}$ & guerra & pica-pau \\
\hline ayõr-ewá & "dizer a namorada" & adultério & $\begin{array}{c}\text { facão } \\
\text { arara } \\
\text { guariba }\end{array}$ \\
\hline lab-ãa-ewá & $\begin{array}{l}\text { "dizer a construção de } \\
\text { maloca" }\end{array}$ & festa & $\begin{array}{l}\text { gavião } \\
\text { marimbondo }\end{array}$ \\
\hline
\end{tabular}


NÃO.HUMANO-PL-linguagem), "a linguagem dos espíritos xamânicos"; sobageykoe (sobag-ey-koe, animal-pLlinguagem), "a linguagem dos bichos". Neste caso, assume-se que estes koe constituem sistemas significantes semelhantes às linguagens humanas, e que alguns humanos (xamãs, caçadores expertos) têm a capacidade de entendê-las parcialmente ou falá-las imperfeitamente. Ademais, usa-se a palavra koe para aludir ao grito específico de um animal, desconsiderando aqui seu valor semântico, considerando apenas sua função de identificação taxonômica: wakoyakoe (wakoya-koe, mutum-linguagem), "o grito do mutum"; tamõapkoe (tamõap-koe, jacu-linguagem), "o grito do jacu".

Enfim, emprega-se a mesma palavra para se referir à voz própria de um indivíduo, geralmente humano e bem conhecido: xikoepaor (xi-koe-paor, 3sG-linguagembonito), "a voz bonita dele". Todas estas formas de "linguagem" são supostamente significantes. Com certeza, nenhuma destas "linguagens" tem a capacidade de expressar tudo. Cada uma pode ser falada apenas por determinados locutores. Todas ficam limitadas a certas espécies de locutores e a algumas áreas conversacionais: há enunciados que não são possíveis de serem traduzidos do suruí para o português, do suruí para a linguagem dos jacus, ou da linguagem dos espíritos para o suruí. A razão disto é simples: não se fala dos mesmos sujeitos com parentes, inimigos, espíritos, xamãs, presas, etc. Então, um koe sempre define ao mesmo tempo um instrumento semiótico, um coletivo de locutores e um campo de significados possíveis.

Quando os Suruí descrevem um gênero lírico como koe, eles o consideram como uma "linguagem" própria a uma situação, ou seja, a um tipo de interação entre determinados atores. Assim, cada gênero lírico estabelece uma relação estreita entre um significante, que é uma forma estética (musical e poética), e um determinado conjunto de significados, que são definidos pelos contextos em que se pode usar esta forma. Tal relação implica uma dupla restrição: os cantos de um gênero podem ser cantados apenas no contexto próprio a este gênero; naquele contexto, só se pode falar a linguagem apropriada, quer dizer, compor e entoar cantos deste gênero. Isto explica a estreita que existe entre a forma musical e a forma poética num gênero lírico, que são designados por uma palavra só (koe). Com efeito, quando eu pedi a alguns homens suruí que cantassem uma mesma frase com várias sonoridades, ${ }^{6}$ todos responderam que o que eu pedia era impossível: não tinha como entoar uma frase de estilo festivo numa sonoridade guerreira, e inversamente. Assim, o aspecto semântico (o padrão metafórico) e o aspecto musical (a sonoridade) são inseparáveis numa "linguagem".

\footnotetext{
${ }^{6}$ Para estas perguntas, eu tive que me voltar para o português (o "som da guerra", o "som da festa"), em razão da falta de termos vernáculos para distinguir o aspecto semântico e o aspecto musical do koe.
}

Além disso, a forma cantada em geral é inseparável do contexto de enunciação. Nos contextos em que se enunciam cantos, não se pode falar à toa. Nessas ocasiões, o uso da linguagem comum, na sua forma falada, é estritamente controlado e limitado: os eventos devem ser "ditos" (-ewá) da maneira certa, isto é, cantada. Assim, quando alguém voltava vitorioso da guerra, evocar sua vítima na linguagem falada seria muito perigoso para ele, porque ela atrairia a vingança mágica da vítima contra a sua família. No contexto festivo, a fala de pessoas bêbadas, se não for cantada, é muito criticada: a única atitude digna para os bêbados é dançar e cantar; qualquer outro comportamento - chorar, cair, gritar, gaguejar, como acontece amiúde - é ridículo e estigmatizado pelos comentários dos espectadores da festa e dos produtores da chicha. Em caso de adultério, falar na cara do marido enganado seria obviamente perigoso.

Nos outros contextos em que os eventos são marcados pela enunciação de cantos, ligados à apropriação de bens raros ou prestigiosos, falar expõe os indivíduos a reclamações e disputas. Em consequência, dessas interações que dão lugar à composição de um canto, só podem ser descritos dois aspectos opostos. De um lado, o canto tem que evocar as características mais genéricas da interação pelo desempenho do padrão metafórico adequado ao gênero lírico em questão. De outro lado, o cantor deve inventar um leitmotiv que seja novo e único, para denotar a singularidade deste evento. Assim, o que na forma cantada se pode descrever dos eventos que merecem ser cantados é o que pode ser capturado num leitmotiv capaz de ser inserido em um determinado padrão metafórico. Esta articulação entre leitmotiv e padrão metafórico impõe uma restrição importante na inventividade semântica dos compositores, pois, se tiverem que falar de gaviões, marimbondos, etc. (como nos cantos de construção de maloca), não poderão usar as mesmas imagens de quando falam em urubus, queixadas, etc. (como exemplo, o padrão dos cantos de guerra).

\section{As condições de enunciação dos cantos}

No contexto originário da composição de um canto, é apenas o autor do ato que legitimou a sua composição que pode cantá-lo, isto é, na terminologia de Goffman, ser o "animador" deste discurso. Aqueles que não participaram deste ato devem ser ouvintes silenciosos, que sequer precisam comentar diretamente este canto, ou compor um próprio. Com efeito, no caso de um canto de guerra, quem não houvesse matado um inimigo ou pretendesse ir à guerra deveria se manter discreto e acanhado. No caso dos cantos de festa, quem produz e oferece chicha não pode cantar, a não ser na última etapa do ciclo ritual; quem não produz chicha, ou é convidado para tomá-la, é um indivíduo pobre e obscuro que não tem condição de criticar publicamente os homens poderosos que estão participando da festa. No caso de um canto de adultério, 
o marido enganado não tem motivo para tornar ainda mais pública a sua situação ridícula.

Esse monopólio inicial do cantor sobre a sua canção contrasta com a situação ulterior. Depois que um canto foi composto e cantado, todos podem cantá-lo, seja com fins recreativos, se gostaram dele, seja para evocar o evento que motivou a composição desta música. Com certeza, o compositor ainda pode enunciar sua própria canção. Porém, isto não é tão simples como era logo depois de cumprir o ato que legitimou a composição. Assim, ele agora deve esperar que alguém lhe solicite cantá-la de novo - este pedido pode acontecer se essa pessoa afirmar ter gostado do canto, ou se ela perguntar sobre os eventos que motivaram a composição. De fato, acontece que um compositor enuncia espontaneamente um canto seu, mas ele deve aproveitar a oportunidade de uma atividade relacionada àquela que motivou a composição do canto: por exemplo, ao fabricar flechas, um homem pode entoar um canto de guerra; ${ }^{7}$ ao confeccionar um cocar, ele pode entoar um canto de festa. Isto não constitui uma regra explícita. É mais uma questão de limitar a bravata que nasce da discordância inevitável entre um contexto enfadonho e um enunciado lírico que se refere a atos gloriosos ou pretensiosos.

Por isso, para que um canto seja "animado" (no sentido de Goffman) e lembrado, ele precisa mais do apoio do outro do que apenas de seu autor, quando o ato que motivou compô-lo está distante no tempo. Entre os dois tipos de contexto de enunciação de um canto, o primeiro da composição e os posteriores da rememoração, há uma diferença marcante. No contexto inicial, o autor do canto controla a enunciação. Depois, ele precisa de "coanimadores" para entoá-lo de novo, na dinâmica da conversação. Os assuntos que trazem uma conversação até a reanimação de cantos antigos são aqueles em que negócios do passado são discutidos. No contexto cultural suruí contemporâneo, estes assuntos surgem frequentemente quando algumas pessoas se reúnem à noite para conversar numa atmosfera tranquila, ou quando um grupo de trabalhadores descansa numa roça. Assim, é quase sempre entre parentes próximos que estes assuntos são discutidos, em situações nas quais a fala está mais voltada para o divertimento do que para o debate ou a firmeza de opinião. É mais importante permitir que as pessoas continuem falando do que reduzir os interlocutores ao silêncio.

\section{Os cantos e as informações históricas}

Ora, os cantos merewá cumprem um papel central na construção da memória histórica entre os Suruí porque as evocações dos eventos passados quase sempre se articulam com a citação de um canto.

A primeira influência dos cantos sobre a memória histórica se verifica na escolha dos assuntos das narrativas

\footnotetext{
${ }^{7}$ Nesta situação, pouco depois de uma vitória, um guerreiro poderia inclusive compor um novo canto sobre o mesmo evento.
}

históricas. O sistema dos gêneros líricos seleciona os tipos de fatos que são "eventos" verdadeiros, ou seja, aqueles que merecem que as pessoas se lembrem deles. Como são apenas alguns tipos de fatos capazes de proporcionar a motivação e o assunto de um canto, a memória histórica se concentra neles. Com efeito, muitos acontecimentos que aparentemente são importantes, significativos, dignos de memória - por exemplo, nascimentos, casamentos, falecimentos - mas não são celebrados por qualquer gênero de cantos, acabam relativamente esquecidos. Com certeza, os Suruí não se esquecem do nascimento de seus filhos, do seu casamento ou da morte de seus parentes, mas as evocações destes acontecimentos não são tão frequentes como as dos eventos em que cantos foram compostos. As lembranças destes fatos não são tão vivas e exatas como as dos cantos e das circunstâncias da sua composição.

Esta potência mnemônica dos cantos tem razões intrínsecas na fala cantada em geral - como a saliência sonora e prosódica, a duração do turno na conversação ou nas formas mais amplas desta arte verbal - a estrutura paralelística. Todas elas ultrapassam o âmbito deste artigo etnográfico. Contudo, outras razões são próprias à teoria suruí da linguagem, à estrutura retórica dos cantos e à prática da citação de peças cantadas na conversação. Aqueles últimos processos serão analisados aqui.

A teoria da linguagem que associa um determinado assunto com uma certa forma de expressão (koe) - os negócios dos Zoró com a língua zoró, os namoros dos jacus com os gritos dos jacus, a alegria da chicha com os cantos de festa, a glória do matador com o canto de guerra, etc. - indica que qualquer acontecimento nunca possa ser perfeitamente "dito" como o foi pelo canto composto logo após ter sido realizado. Naquele momento, o autor e animador do canto estava estreitamente conectado com seu próprio ato e a forma do discurso estava claramente adequada ao contexto. Deste ponto de vista, entende-se que a reprodução tão exata quanto possível, sob todos os aspectos - conteúdo lexical, prosódia, ar musical, etc. - deste canto possa aparecer como a melhor denotação do evento em questão. De fato, quase todas as narrativas históricas ${ }^{8}$ suruí incluem a citação de um canto, que amiúde fica numa posição-chave: algumas vezes no começo da narração de um episódio, muitas vezes na conclusão. 0 resto do discurso aparece como um comentário ou como uma introdução e situação do canto, que no simples nível quantitativo representa uma boa parte da duração da narrativa, às vezes mais do que a metade dela.

\section{Contudo, se esta escolha parece lógica de um ponto de}

\footnotetext{
8 "Narrativa histórica" não constitui uma categoria explícita em suruí. Não há um termo metalinguístico para se referir a este tipo de discurso e distingui-lo de outro tipo de narrativas, por exemplo, das narrativas mitológicas. Mas estes dois gêneros narrativos têm formas bastante distintas, em particular, no plano do seu uso das partículas gramaticais que indicam a fonte da informação (relato pessoal ou boato anônimo), o que comprova que os Suruí não os assimilam.
} 
visto emic, isto é, nas concepções suruí da linguagem, ela parece difícil de comprovar de um ponto de vista etic. Com efeito, quando se examina uma narrativa histórica, as informações sobre os eventos ocorridos que podem se extrair do discurso parecem bem fracas à primeira vista. Consideremos o exemplo (3), que é um extrato de uma interação conversacional entre a narradora - uma velha mulher recém-viúva - um velho homem, algumas meninas e eu. Esta narrativa corresponde a um turno numa conversação na qual os dois velhos evocavam lembranças da sua juventude. A mulher espontaneamente começou a contar um evento de que se orgulhava um pouco: uma festa de chicha em que ela a ingeriu, o que é um acontecimento muito raro na vida de uma mulher.

(3) "Foi muito tempo atrás. Nós íamos fazer a festa das preguiças [um tipo de festa de chicha]. Alguém [imprecisão eufêmica para se referir ao marido recémfalecido da narradora] me falou: "Você tem que ir lá sozinha, com as preguiças, para nossos filhos". Eles [os tomadores de chicha] entraram [numa maloca] de dia; quando ele [o marido] viu isso, ele me falou: "Vai lá sozinha, para meus filhos". Então eu fui lá. Eu entrei, tomei a chicha. Tirei minha máscara, tirei minha pele, e dancei, com meu facão na mão.

\author{
"Ana toyhxi yã" \\ "Ana toyhxi yãa" te ihiwayaihkanẽyey oğay ekanan ne \\ kaledma ihiwayaihkanẽyeyibebnota te tamaihkabi oĩ \\ ma ena, oma wa, oma ena \\ "Ika ekah ma, ihiwayaihkar ekah" ihiwayaihkama te \\ ğapomnihariwoyey, ihiwayaihkanẽyey oğay ekanan \\ ena, oma wa, oma wa ena \\ "Ana toyhxi yã" \\ "Ana toyhxi yã" te ğapomnihariwoyey oğay \\ ekanan ne kaledma ğapomnihariwoyeyibebnota te \\ ihiwayaihkabi oĩ, oma wa, oma ena \\ "Ika ekah ma" \\ "Ika ekah ma, omaanarsegahixoperemaki \\ ihiwayaihkar ikay ma" anarsegahakad oğay eka, \\ oma wa, oma ena, anarsegahakadanarsegahixoer \\ aĩ, oma wa, oma ena... \\ "Ana toyhxi yõ" \\ "Ana toyhxi yã" te mõboiwayakayey oğay ekanan \\ ne kaledma tamamóboiwayaihkabi oĩ taibebnota \\ te ma oĩ, oĩ ena \\ "Ika ekah ma"
}

"Ika ekah ma, mõboiwayakayey yã, mõboiwayeseẽekar ikay ma" anarsegahakad oğay eka oma wa, oma ena...

"Nós outros estamos fazendo assim", ainda que aqueles que desejam a chicha do dono da chicha não me convidassem assim, eu entrei atrás daqueles que desejam a chicha do dono da chicha e estava falando assim, sim, eu fiz isso

"Vai lá procurar a chicha do dono da chicha", ainda que aqueles que fazem soar a escuridão não me convidassem assim para provar a chicha do dono da chicha, aqueles que desejam a chicha do dono da chicha, eu fiz isso, sim, eu fiz isso

"Vai lá, mande o espírito da minha cabeça cabeluda procurar a chicha do dono da chicha", quando o matador de cabeça cabeluda me falou assim, eu fiz assim, sim, eu fiz, entrar de pé o espírito da cabeça cabeluda do matador de cabeça cabeludo, eu fiz isso "Nós outros estamos fazendo assim", ainda que os matadores dos donos da cachoeira não me convidassem assim, eu entrei atrás deles até a chicha do dono da cachoeira deles, sim, entrei assim

"Vai lá, assim falam os matadores do dono da cachoeira, vai preparar o caldo do dono da cachoeira", quando o matador de cabeça cabeluda me falou assim, eu fiz assim, sim, fiz assim

Eu disse (-ewá) isso. Eu disse isso porque alguém me avisou (-ma) "Eu estou falando que você vai dizer (-ewá) isso". Eu vim sozinha onde os outros estavam preguiças. Aí eu disse isso, como uma preguiça".

Esta narração mostra um conjunto de detalhes pouco significativos ("eu dancei com meu facão na mão"); de redundâncias ("tirar sua máscara e pele", "estar como preguiça", todos aspectos intrínsecos à festa das preguiças, e que estão também denotados pelo gênero da música); e de elipses e silêncios. Além da omissão da identidade do interlocutor (que os interlocutores suruí podiam inferir), a narradora não explica por que o marido dela não foi tomar chicha, nem como ela teria sido: não se saberá se a chicha era gostosa, abundante ou amarga, ou se a dança era bonita ou feia, etc. A citação do canto parece suficiente par dar conta deste evento: o fato de ter composto um discurso em fala cantada atesta que algo importante ocorreu e o conteúdo cantado resume os aspectos relevantes deste acontecimento. Ou melhor, a conformidade musical e estilística deste canto com o gênero lírico "dizer a preguiça" atesta que a autora cumpriu corretamente a tomada da chicha no jeito chamado "das preguiças". No entanto, a singularidade deste canto - isto é, a singularidade lexical e prosódica do seu leitmotiv - explica a singularidade da ocorrência deste rito. Além da certeza da atuação ao mesmo tempo original e de acordo com a norma, fica difícil inferir qualquer sequência de eventos de um canto como aquele que esta narrativa cita.

Contudo, o conteúdo informativo do próprio canto não é desprezível para quem sabe analisá-lo no contexto suruí. Além das metáforas (por exemplo, ğapomnihiwayey, "os donos da escuridão") e da forma musical que o classificam como uma peça musical cuja composição foi motivada pela participação numa festa de determinado tipo, "a festa das preguiças" - uma tomada noturna de chicha na qual os bebedores estão usando máscaras longas - o canto inclui informações muito particulares. Estas dizem respeito à situação da autora no momento da composição. Assim, a insistência do leitmotiv na falta de 
convite se refere ao incômodo de uma esposa em festejar sem o marido e à audácia de que ela precisa para fazer isto. Também a expressão "matador de cabeça cabeluda" constitui uma alusão ao homicídio de um índio cinta larga por seu marido alguns anos antes, porque "cabeça cabeluda" é uma metáfora habitual nos cantos de guerra para se referir aos Cinta Larga (um povo vizinho que mora a leste dos Suruí).

Enfim, a metáfora dos "donos da cachoeira" é provavelmente a mais importante do ponto de vista histórico, pois ela permite "datar" a música e o evento como ocorridos num determinado ciclo ritual, o da "chicha de caldo de donos da cachoeira". Com efeito, por meio de algumas metáforas, todas as músicas de festas podem ser referidas a um ciclo ritual que se desenvolveu durante um ano. Na abertura do ciclo, no começo da estação chuvosa (mais ou menos em novembro), a chicha do ano recebia um "nome": num ritual específico o líder de uma facção desafiava outro líder a produzir e a oferecer-lhe uma chicha simbolicamente diferente das chichas anteriormente consumidas. Por isso, ele a chamava segundo uma metáfora ainda inusitada contudo, a chicha ficava preparada exatamente com a mesma receita. Ele escolhia um nome para ela no campo semântico das bebidas feitas de produtos selváticos ou animais - invertendo o caráter eminentemente vegetal e hortícola da chicha - e procurava singularizá-lo por meio de um atributo incongruente ou cômico. Este nome será usado pelo produtor da chicha para convidar os bebedores a tomá-la durante todo o ciclo, até a festa final no fim da estação seca (em agosto ou setembro). Em todas as festas do ciclo, os bebedores da facção do inventor do nome tentavam inserir este nome nos cantos que eles compunham, como no exemplo (3).

Se muitos líderes faccionais desafiavam produtores de chicha, podia haver vários - até três ou quatro - nomes

Tabela 2. Calendário histórico dos nomes de chicha

Table 2. Historical calendar of beer names

\begin{tabular}{|c|c|c|}
\hline Nome da chicha & & Data provável do ciclo ritual \\
\hline Marãyasi & Chicha de cana de açucar & na década de 1920 \\
\hline Lorğapsi & Chicha de fruta lorğap & na década de 1930 \\
\hline Yoykapsi & Chicha de patuá & na década de 1930 \\
\hline Agoyasi & Chicha de figueira & na década de 1930 \\
\hline Sarikapli & Chicha de fruta sarikap & na década de 1930 \\
\hline Payaysi & Chicha de capim & na década de 1940 \\
\hline Ihkartihsi & Chicha da lagoa grande & 1944 \\
\hline Wudwudeysi & Chicha de abelhas wudwudey & 1944 \\
\hline Orixiasi & Chicha de caju & 1945 \\
\hline Morarasi & Chicha de tatu & 1946 \\
\hline Watãrğãyyosi & $\begin{array}{l}\text { Chicha de pó de poste } \\
\text { telegráfico }\end{array}$ & 1946 \\
\hline Yokurasikot & Suco de abóbora & 1948 \\
\hline Wasapoypeapsikot & Suco de estrada de cavalo & 1948 \\
\hline Awurueyxẽh & Caldo de cachorro & 1955 \\
\hline Moribtiheyxẽh & Caldo de boto & 1955 \\
\hline Amõtiheyxẽh & Caldo de jabuti grande & 1959 \\
\hline Ğopamnexẽh & Caldo de peixe elétrico & 1959 \\
\hline Maraiasi & Chicha de cará zoró & 1960 \\
\hline Ibaptihsi & Chicha de canoa grande & 1960 \\
\hline Atamasẽh & Chicha de fruta atama & 1960 \\
\hline Itxieyxẽh & Chicha de veados & 1960 \\
\hline Mẽbeeyamayobapsi & $\begin{array}{l}\text { Chicha de atoleiro das } \\
\text { queixadas }\end{array}$ & 1964 \\
\hline Waotiheyxẽh & Caldo de carros & 1966 \\
\hline Ğoñoasi & Chicha de fruta ğoñoa & 1969 \\
\hline Ğapatireyxi & $\begin{array}{l}\text { Chicha de marimbondos } \\
\text { dolorosos }\end{array}$ & 1969 \\
\hline Ğammeptağeyxi & Chicha de marimbondos pretos & 1971 \\
\hline Ipetoreysi & Chicha de fruta ipetor & 1971 \\
\hline Pasaptihahsi & Chicha de coco & 1979 \\
\hline Mõboiwayeyxẽh & Caldo de donos da cachoeira & 1979 \\
\hline Loğloğahsi & Chicha de fruta loğloğah & 1980 \\
\hline Xiporeyeyeplikot & Suco do lamaçal das ariranhas & 1980 \\
\hline Maçãesi & Chicha de maçã & 1985 \\
\hline Sarĩnanahsi & Chicha de fruta sarĩnanah & 1985 \\
\hline
\end{tabular}


de chicha em uso no decorrer de um ano. ${ }^{9}$ Uma parte considerável dos Suruí é capaz de ordenar estes nomes cronologicamente. Com certeza, não são todos os Suruí que têm esse conhecimento, apenas os relativamente velhos - aqueles com mais de 40 anos - talvez porque só eles ousam reivindicá-lo. Ademais, mesmo os melhores peritos têm dificuldade para recitar uma lista "completa" destes nomes em ordem cronológica - porque isto é um exercício que ninguém pratica. Contudo, esta lista implícita constitui um calendário histórico: um instrumento cognitivo para orientar-se no tempo e ordenar cronologicamente os eventos (ver Tabela 2). Quando alguém cita uma música numa narrativa, os ouvintes peritos na memória histórica podem situar o evento no calendário por meio destas alusões ao nome da chicha do ciclo - assim, o evento do exemplo acima pode ser situado em 1979 pela presença da expressão mõboiwayey, "dono da cachoeira", no canto. Referindose a este calendário, o corpus dos cantos disponíveis na memória dos Suruí representa os anais das interações festivas.

Isto funciona de maneira direta somente no caso dos cantos de festa, porque estes amiúde contêm o nome da chicha do ano festivo. No entanto, o calendário dos nomes de chicha funciona de maneira indireta com as narrativas que tratam de outros tipos de eventos. Com efeito, se alguém perguntar "Quando aquele evento ocorreu?" - evento que já está destacado por um canto a reposta mais comum será "Quando nós morávamos na aldeia X". Ora, o nome de cada aldeia era dado a partir do nome da chicha de um ciclo ritual que tinha sido realizado ali - cada um se apresenta como um sintagma do tipo "o lugar onde a chicha X foi tomada". Então, situar um evento no tempo é sempre destacar um canto citando-o e assinalando-o em referência a um conjunto de outros cantos ordenados cronologicamente, tendo como base uma lista de metáforas - uma lista que, antigamente, era regularmente acrescida daquelas que eram criadas em novos ciclos rituais. Isto implica que toda evocação de um evento, vinculado direta ou indiretamente a um canto, suscitará a evocação de outros cantos e criará uma dinâmica conversacional de citações sucessivas de vários cantos.

\section{Efeitos sobre a estrutura narrativa da memória histórica}

A focalização das narrações na citação de um canto para ressaltar um evento tem efeitos importantes no vínculo narrativo de um episódio com o próximo. Cada episódio é equivalente à citação de um canto, introduzida por algumas informações sobre as circunstâncias da sua composição. Por isso, o vínculo entre dois eventos narrados é determinado pelos critérios que definem um

\footnotetext{
${ }^{9}$ Acontecia também de um líder tomar a iniciativa de produzir uma chicha sem ter sido desafiado anteriormente por um bebedor; neste caso, o próprio produtor nomeava a chicha.
}

canto: autor, gênero lírico, circunstâncias de composição e estilo poético. Em consequência, as histórias suruí estão estruturadas por alguns tipos de vínculos entre episódios, quer dizer, entre cantos.

O vínculo mais frequente entre episódios centrados num canto é a identidade do autor. Muitas narrativas enumeram as músicas de um determinado autor sem respeito à ordem biográfica. A preeminência poética parece ter mais importância na escolha dos cantos citados, como no exemplo (4), extraído de uma conversação entre dois homens adultos.

(4) Meu avô cantava muito. Ele dançava muito, mais que os outros. - Ele estava assim? - Sim. Ele fazia muitos pedidos rituais de chicha. - Ele fazia assim? - Sim, fazia isso. [...] Um dia, pessoas do clã Marimbondo-Branco pegaram ele quando ele estava sozinho. Elas Ihe ofereceram muita chicha. Ele vomitava só. - Ele vomitava só? - Sim. Eles não deixaram ele sair [vomitar no lugar próprio]. Ele passou para acima deles e saiu no terreiro, para vomitar. E parou. Eles pegaram ele de novo, e ofereceram mais chicha. Ele ficou de pé no fundo da maloca [lugar do chefe]. Lá, o pai de teu sogro lhe ofereceu mais chicha. [Segue a lista dos doadores de chicha e alguns detalhes sobre a interação]. Contudo, ele não caiu. Ele não estava bêbado. Por isso ele falou:

Otağa te ma, moya sor e taro perekabi, yenam eka te ke ohgoy a, ohgoy a

Eu estou bem, por causa da ação do copo da velhinha feia, quando este é fraco, eu desce, eu desce, pessoas estão falando

Ele falou isso. - Ele falou muito? - Sim, muito! Outra vez ele falou sobre aquele que matou um inimigo:

\section{Ã ikõrnih sa awepika oğay a Masayey epika oğayki oğay a Ã nãbekodiway xereg peba awepika oğay a, akadğa oğay a}

Este é o Grande-Gavião que se vinga de mim, pessoas falam assim

Ele se vinga do que eu lhe fiz em vingança do que ele fez aos macacos, pessoas falam assim

Este é o dono do facão vestido de preto que se vinga de mim, do matador dele, pessoas falam assim

- Ele falou muito. - Sim. O pai dele não tomava muito chicha. [A narração volta à excelência do avô como tomador de chicha, com citações de outras músicas de festa]

Nesta narrativa, o segundo canto citado é um canto de guerra, que diz respeito a um evento anterior e sem nenhuma relação causal com os eventos aos quais o 
narrador se referiu anteriormente e posteriormente. O único motivo desta citação é atestar a excelência do indivíduo em vários gêneros de cantos e, em consequência, em vários campos de ação.

Um outro tipo de vínculo bastante comum é a identidade de gênero em narrativas que citam cantos de vários autores, e que aparecem às vezes sem respeito à ordem cronológica, como no exemplo (5), no qual o primeiro canto tinha sido composto pelo próprio narrador. O canto constituiu o início mesmo da conversação e da narrativa: o narrador começou a cantarolá-lo num momento de silêncio, quando os interlocutores pareciam cair no sono, deitados em suas redes ao anoitecer.

(5) Ano Tamõup peremi oje pama hwepi sonima koy oje ăgihr poy kaled aki pama ixiboga amiĩ eka yã te oli $i$

Ana te bo oya ana i te oliyã

Lá, como Pequeno-Jacu, lá na imensidão rio abaixo, eu tomei a espuma da nossa água por uma praia e caí, eu estou falando isso, sim

Eu fiz assim, eu estou falando assim

- Por que você fala "Pequeno-Jacu"? Quem é isso? - Sim, falei assim [canta de novo] - Por que "Pequeno-Jacu"? Por que você não fala "Grande-Jacu" [personagem mitológico mais conhecido]? - Sim. "Grande-Jacu" [canta de novo, corrigindo-se]. Eu falei assim, quando um seringueiro [que o narrador roubava] atirou em mim. [Segue uma discussão sobre as peripécias deste roubo. Depois de um silêncio:] Ai [alguém] chegou [o narrador começa cantarolando:]

\section{Mamahgey peresaga wa oya, owekaya}

Eu sou o chefe dos jovens, eu falei assim, sobre mim, pessoas falam assim.

Ele falou assim quando ele tomou facões no lugar da grande árvore atama [um seringal]. [O narrador cita três músicas do mesmo autor antes de esclarecer a sua identidade.]

Aqui a citação dos cantos de um outro cantor, do mesmo gênero lírico, aquele que trata do roubo de ferramentas metálicas, parece motivada parcialmente pelo desejo de legitimar o caráter inovador do próprio canto do narrador, depois que foi criticado pela interlocutora.

Um outro tipo de vínculo frequente é a semelhança de circunstâncias de composição ou a sua simultaneidade. É comum citar vários cantos que foram motivados por um mesmo evento, quando havia vários participantes que o cantaram. Tal vínculo é provavelmente o que parece ser o mais narrativo. Contudo, o importante para os narradores é que eles descreveram todos os aspectos do evento através das citações de tudo o que foi "dito" (ewá) sobre este evento.

Enfim, alguns vínculos parecem tão difíceis de esclarecer que só é possível explicá-los como ecos poéticos. Assim, no exemplo (6), uma discussão entre uma mulher e eu não tem nenhum vínculo narrativo explícito entre os dois episódios. Os cantos citados diferem pelos autores, pelos gêneros e pelas ocasiões das composições.

(6) Ğaratihmă̆a ite te õmner ke emereya ani i Loykubeypeegohbaã xite omner ke emereya ani $i$ Não é por nada que você abriu uma roça grande muitas vezes

Não é por nada que você roubou o milho vermelho dos inimigos muitas vezes

Eu falei isso porque eu tinha preparado a chicha. [Segue uma discussão sobre o tempo em que isso aconteceu]. Foi aqui, pouco distante daqui que nós estamos que eu falei assim. [Um silêncio e a narradora começa cantarolando.] Meu pai falava isso:

\section{Omáh ğaratihmakiyey awekay $i$ \\ Omáh loykubey awekay $i$ \\ Meegohbaã aye pami yã taya awekay $i$ \\ Os que abrem roças grandes estão falando de mim Os inimigos estão falando de mim \\ Ele roubou nosso milho vermelho, eles estão falando de mim}

Aqui é uma expressão de importância secundária que parece constituir o vínculo mais destacado entre os dois cantos: meegohb, "milho vermelho", um cultivar tipicamente zoró, que não entra nos padrões metafóricos específicos de qualquer gênero lírico. Esta expressão constitui apenas uma marca estilística própria a alguns autores (Yvinec 2011b). Estes estilos são amiúde transmitidos de pais para filhos, como neste caso. Então, chegamos ao último grau da determinação das estruturas narrativas históricas pela arte verbal que mantém as lembranças dos eventos pertinentes no contexto cultural suruí: o relato histórico se desenvolve na conversação conforme uma lógica mais estética do que narrativa.

\section{Conclusão}

O caso dos cantos merewá entre os Suruí demonstra que nas tradições orais das populações indígenas da Amazônia - ou pelo menos em algumas destas - há artes verbais que cumprem o papel de formar e transmitir a memória histórica. As conclusões que se podem tirar deste fato concernem a duas áreas.

Na área da etnologia da Amazônia indígena, o caso suruí aponta que estes povos têm uma historicidade própria que se realiza em gêneros discursivos específicos e distintos dos discursos históricos da tradição ocidental. O estudo desta(s) historicidade(s) amazônica(s) deveria deixar de caracterizá-la(s) negativamente em contraste com a historicidade ocidental - como historicidade(s) "fria(s)" versus uma historicidade quente. Ao contrário, os estudos da temporalidade e da historicidade amazônicas 
precisam se voltar para uma comparação detalhada das formas retóricas e dos usos pragmáticos das artes verbais que transmitem as lembranças históricas nestas sociedades. Em muitos casos, cantos e músicas cumprem este papel: por exemplo, no Alto Xingu (Basso 1985), entre os Kayabi (Travassos 1993; Oakdale 2005), os Yanesha (Smith 1977; Santos-Granero 2007) ou os Wayana (Chapuis e Rivière 2003).

A outra conclusão concerne à antropologia da historicidade. Com certeza, seria difícil negar que todas as formas de discurso histórico requerem uma dimensão narrativa mínima (Ricœur 1983), porque qualquer evocação de vários eventos conduz a pôr, pelo menos implicitamente, uma relação causal ou temporal entre eles. Contudo, os cantos suruí demonstram que às vezes uma memória histórica pode se construir com base em instrumentos mnemônicos que não são intrinsecamente narrativos. Ademais, as narrativas em que estes cantos são inseridos como citações não estão sempre estruturadas pelos vínculos narrativos básicos, sucessão temporal e/ou causal, mas constituem narrativas "abertas" (Ochs 2004), que são estruturadas por vínculos de natureza retórica ou estética. A análise comparativa das várias formas de historicidade deveria começar por um estudo dos gêneros discursivos e das interações conversacionais em que a memória do passado se realiza.

Paris, 30 de junho de 2016

\section{Agradecimentos}

Eu quero agradecer a Simone Silva e Lucía Tennina por ter me convidado em Niterói para as jornadas de Etnografia da Linguagem em outubro de 2015, onde este artigo foi apresentado e discutido. A Fondation Thiers e o projeto ANR Fabriq'Am financiaram meus trabalhos nestes últimos três anos. Eu agradeço também a todos os Suruí que aceitaram minha pesquisa etnográfica, me hospedaram e me ensinaram suas artes verbais.

\section{Referências bibliográficas}

Basso, E. (1985). A Musical View of the Universe: Kalapalo Myth and Ritual Performances, University of Pennsylvania Press, Philadelphia.

Chapuis, J., H. Rivière. (2003). Wayana eitoponpë. (Une) histoire (orale) des Indiens Wayana, Ibis Rouge, Cayenne.

Chiappino, J. (1975). The Brazilian Indigenous Problem and Policy: The Aripuanã Park, IWGIA, Copenhagen.

Fausto, C., M. Heckenberger. (2007). Indigenous History and the History of the "Indians". Fausto, C., M. Heckenberger, Time and Memory in Indigenous Amazonia: Anthropological Perspectives, 1-43, University Press of Florida, Gainesville.

Goffman, E. (1979). Footing. Semiotica, 25 (1): 1-29.

Mindlin, B. (1985). Nós Paiter: os Suruí de Rondônia, Vozes, Petrópolis.

Oakdale, S. (2005). I Foresee My Life: The Ritual Performance of Autobiography in an Amazonian Community, University of Nebraska Press, Lincoln.

Ochs, Elinor. (2004). Narrative Lessons. Duranti, A., A Companion to Linguistic Anthropology, 269-289, Blackwell, Malden.

Overing, J. (1977). Social time and social space in Lowland South American societies. Actes du XLI/ Congrès international des américanistes, II, 7-394, Société des Américanistes, Paris.

Ricœur, P. (1983). Temps et récit, Seuil, Paris.

Santos-Granero, F. (2007). Time Is Disease, Suffering, and Oblivion: Yanesha Historicity and the Struggle against Temporality. Fausto, C., M. Heckenberger, Time and Memory in Indigenous Amazonia: Anthropological Perspectives, 47-73, University Press of Florida, Gainesville.

Smith, R. (1977). "Deliverance from Chaos for a Song: A social and religious interpretation of the ritual performance of Amuesha music". Cornell University, Ithaca, Estados Unidos, 326 p. Tese de doutorado.

Travassos, E. (1993). A tradição guerreira nas narrativas e nos cantos caiabis. Penteado Coelho, V., Karl von den Steinen: um século de antropologia no Xingu, 445-483, Edusp, São Paulo.

Yvinec, C. (2011a). "Les monuments lyriques des Suruí du Rondônia (Amazonie méridionale): chants, événements et savoirs". EHESS, Paris, França, 1148 p. Tese de doutorado.

Yvinec, C. (2011b). Invention et interprétation : chants de boisson et chants chamaniques chez les Suruí du Rondônia. Journal de la Société des Américanistes 97 (1): 151-177. 